\title{
Epidemiological Aspects of Penile Cancer in Rio de Janeiro: Evaluation of 230 Cases
}

\author{
Leandro Koifman, Antonio J. Vides, Nelson Koifman, João P. Carvalho, Antonio A. Ornellas \\ Department of Urology, Mario Kroeff Hospital (LK, AJV, NK, JPC, AAO), Department of Urology, \\ Souza Aguiar Municipal Hospital (LK) and Department of Urology, National Cancer Institute (NK, \\ AAO), Rio de Janeiro, RJ, Brazil
}

\begin{abstract}
Purpose: To determine epidemiological characteristics of penile cancer in Rio de Janeiro, its associated risk factors and clinical manifestations.

Patients and Methods: Between 2002 and 2008 we evaluated 230 patients at three public institutions, considering age, ethnicity, birthplace, marital status, educational level, religion, tobacco smoking, presence of phimosis and practice of circumcision.

Results: The ages ranged from 25 to 98 years, with an average of 58.35 years. Of the 230 patients, 167 (72.7\%) were from the southeast region of Brazil (which includes Rio de Janeiro) and 45 (19.5\%) were from the northeast of the country. Most patients were white $(67.3 \%)$, married (58.6\%), smokers (56.5\%) and had not completed primary school $(71.3 \%)$. The predominant religion was Catholic (74.8\%). Of the $46(20 \%)$ circumcised patients, only 1 (2.2\%) had undergone neonatal circumcision. Grade I tumors were present in $87(37.8 \%)$ of the patients, grade II in 131 (56.9\%) and grade III in 12 (5.3\%). Lymphovascular embolization was observed in 63 (27.3\%) and koilocytosis in 124 (53.9\%) patients. Of the total, $41.3 \%$ had corpora cavernosa or corpus spongiosum infiltration, and $40(17.4 \%)$ had urethral invasion. Prophylactic lymphadenectomy was performed on $56(36.1 \%)$, therapeutic lymphadenectomy on $84(54.2 \%)$ and hygienic lymphadenectomy for advanced disease on $15(9.7 \%)$ patients. The median time between the lesion onset and clinical diagnosis was 13.2 months. The mean follow up was 28.8 months.

Conclusion: Most of our patients were born in this state and had low socioeconomic status. Most of them were white men, married, smokers, uncircumcised, of the Catholic faith and in their sixties or older. Their disease was in most cases diagnosed only in the advanced stages.
\end{abstract}

Key words: penis; penile cancer; epidemiology

Int Braz J Urol. 2011; 37: 231-43

\section{INTRODUCTION}

Cancer of the penis is a rare neoplasm whose treatment causes devastating effects on patients' physical and mental health. The low incidence of this disease in developed countries in contrast with the high incidence in developing countries clearly indicates the disease's association with local economic conditions (1). Some areas of Brazil have high incidences of penile cancer, reaching about $17 \%$ of all malignant neoplasms in men, thus constituting a serious public health problem (2).

The etiology of penile cancer has not been fully elucidated. However, its incidence varies accord- 
ing to the practice of circumcision, personal hygiene, presence of phimosis, human papilloma virus infection and tobacco use (3-5).

Squamous cell carcinoma represents approximately $95 \%$ of penile cancers. The remaining $5 \%$ of cases result from metastases from tumors in other organs or less frequent tumor types, such as sarcomas, melanomas and lymphomas (6).

The aim of this study was to assess the epidemiological characteristics of penile cancer in the city of Rio de Janeiro, its associated risk factors and clinical manifestations.

\section{MATERIALS AND METHODS}

Between January 2002 and October 2008, 240 patients with malignant neoplasm of the penis were evaluated at three public institutions in the city of Rio de Janeiro. Of the 240 patients studied, 10 (3.9\%) were excluded for lack of histopathological data or clinical or epidemiological studies. Thus, 230 patients remained for analysis. All patients were evaluated using the following epidemiological variables: age, ethnicity, birthplace, marital status, educational level, religion, smoking, presence of phimosis, practice of circumcision and clinical history of sexually transmitted diseases. The clinical and pathological staging was done according to the latest TNM classification system (2002). All patients underwent biopsy of the primary lesion for diagnostic confirmation. Patients were clinically evaluated for the presence of metastases by CT scan of the abdomen, pelvis and chest. All patients were evaluated prospectively and gave their informed consent to participate in the study. Our Institutional Review Board also approved the study. The mean follow up was 28.8 months.

Pathological material was reviewed and all tumors histologically classified based on Broders system. Only two pathologists were responsible for reviewing the specimens. The pathological variables studied were histological type, grade, size of the lesion, corpus spongiosum and/or corpora cavernosa infiltration, urethral infiltration, lymphovascular involvement, presence or absence of koilocytosis (uni or binucleated cells and chromatin surrounded by dark vacuolated cytoplasm).

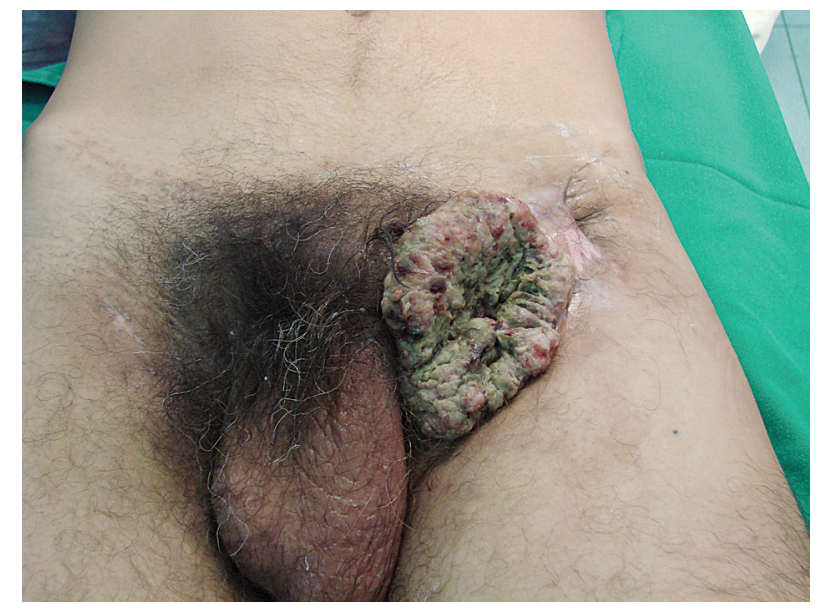

Figure 1 - Patient with large ulcerated metastatic lesion in the inguinal region.

We also evaluated the time between the onset of clinical symptoms and diagnosis. The type of treatment for each patient was included in the assessment. All patients who were indicated for adjunctive treatment of inguinal lymphatic basins underwent radical bilateral inguinal lymphadenectomy. We considered lymphadenectomy to be prophylactic when performed on patients with clinically negative lymph nodes and high risk of inguinal dissemination (PT2 and/or lymphovascular invasion and/or Broders histological classification greater than or equal to II). We considered it to be therapeutic when performed on patients with clinically positive inguinal lymph nodes. Finally, we considered it to be palliative for patients with large ulcerated tumor masses and/or masses fixed in the inguinal region (Figure-1).

Statistical analysis was performed using One Way Analysis of Variance (ANOVA) with Bonferroni post test for comparison between data. A p value < 0.05 was considered statistically significant. Linear regression was performed when studying the stratification of tumor grade in comparison with tobacco use and nonsmoking patients.

\section{RESULTS}

The patients' ages ranged from 25 to 98 years, with a mean of 58.35 years (Table-1). Of the 
Table 1-Number of cases of cancer of the penis distributed by age and corresponding decade of life.

\begin{tabular}{lcc}
\hline $\begin{array}{c}\text { Age Group } \\
\text { (years) }\end{array}$ & $\begin{array}{c}\text { Number of Cases } \\
(\%)\end{array}$ & Decade of Life \\
\hline $21-30$ & $4(1.7 \%)$ & $3^{\text {th }}$ \\
$31-40$ & $16(7 \%)$ & $4^{\text {th }}$ \\
$41-50$ & $46(20 \%)$ & $5^{\text {th }}$ \\
$51-60$ & $61(26.5 \%)$ & $6^{\text {th }}$ \\
$61-70$ & $57(24.8 \%)$ & $7^{\text {th }}$ \\
$71-80$ & $30(13 \%)$ & $8^{\text {th }}$ \\
$81-90$ & $14(6.1 \%)$ & $9^{\text {th }}$ \\
$91-100$ & $2(0.9 \%)$ & $10^{\text {th }}$ \\
Total & $230(100 \%)$ & ----- \\
\hline
\end{tabular}

230 patients evaluated, $155(67.3 \%)$ were white, 55 $(23.9 \%)$ mulatto and $20(8.8 \%)$ black. The distribution of patients in relation to the birthplace is shown in
Figure-2. Of the 230 patients, 167 (72.7\%) were from the southeast region, 45 (19.5\%) from the northeast, 6 (2.6\%) from the north, $6(2.6 \%)$ from the Midwest and $2(0.9 \%)$ from the south of the country. Four $(1.7 \%)$ patients were foreigners. Of the four foreign patients evaluated one came from Israel and other three from Portugal. In this series, 135 (58.6\%) patients were married, 57 (24.7\%) were single, $23(10 \%)$ divorced and $15(6.5 \%)$ widowed. The level of education ranged from illiterate, with $35(15.2 \%)$ patients, to college graduates, with $8(3.4 \%)$ patients. Of the remaining patients, $164(71.3 \%)$ had not finished primary school and $23(10 \%)$ were high-school graduates. The predominant religion was Catholic, with $172(74.8 \%)$ patients, followed by various Protestant denominations, with 31 patients (13.5\%). Only one patient $(0.4 \%)$ was Jewish in this series and another $26(11.3 \%)$ had various other religious beliefs.

In this series $130(56.5 \%)$ patients were tobacco smokers and only $46(20 \%)$ patients had been

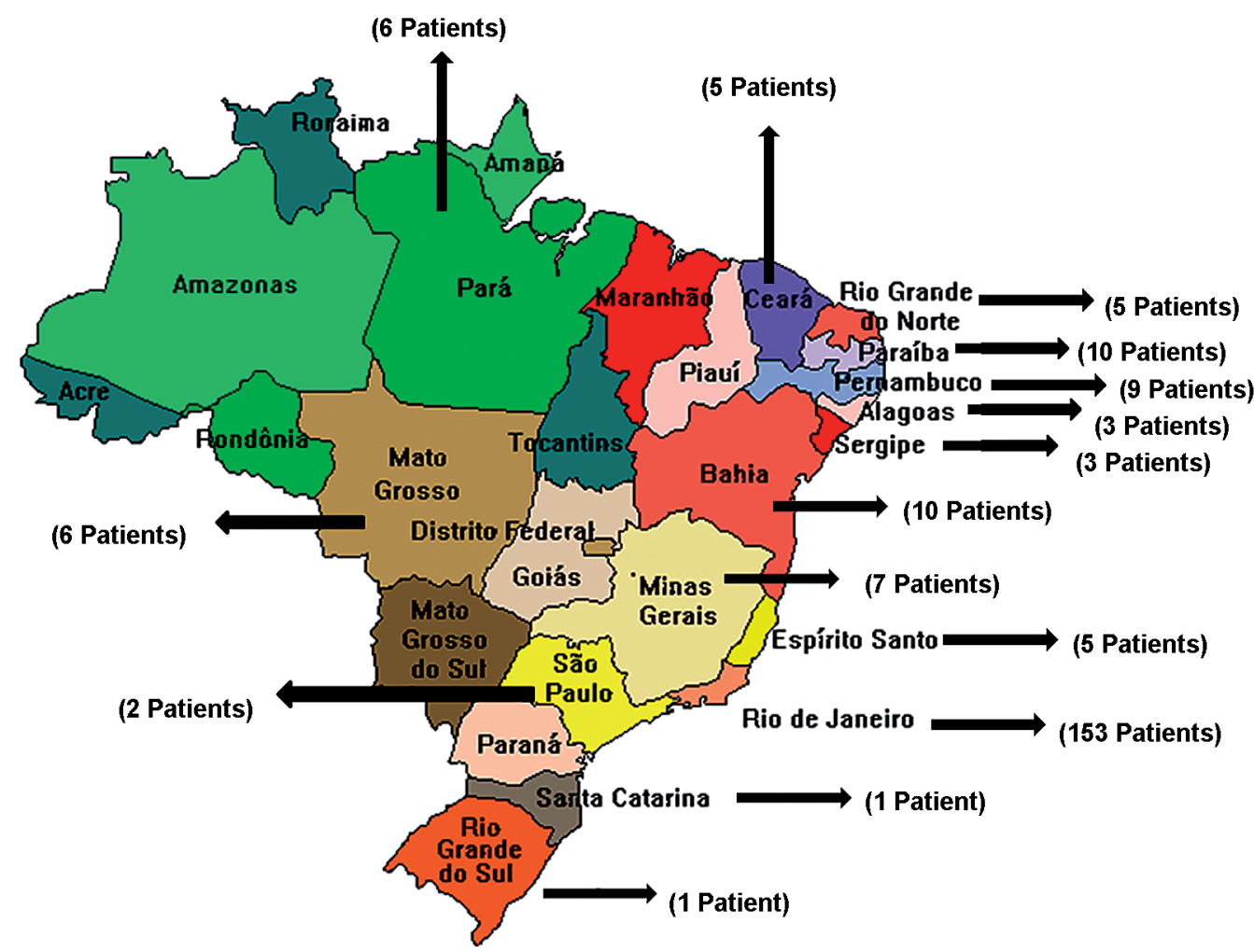

Figure 2 - Geographical distribution by state of birth of patients with tumor of the penis treated in Rio de Janeiro (the total number of patients was lower than 230 cases since 4 patients were foreigners). 
Table 2 - Initial location of penile lesions in $230 \mathrm{pa}$ tients.

\begin{tabular}{lc}
\hline Location of Tumor & N of Patients (\%) \\
\hline Foreskin & $15(6.5)$ \\
Glans & $80(34.8)$ \\
Prepuce and glans & $79(34.3)$ \\
Balano-preputial sulcus & $11(4.8)$ \\
Penile stem & $11(4.8)$ \\
Entire penis & $34(14.8)$ \\
Total & $230(100)$ \\
\hline
\end{tabular}

circumcised. Among circumcised patients, 1 (2.2\%) had undergone neonatal circumcision, while $10 \mathrm{pa}-$ tients $(21.7 \%)$ had been circumcised in adolescence and $35(76.1 \%)$ in adulthood. Of the circumcised patients, $25(54.4 \%)$ had grade I tumors, 18 (40\%) grade II tumors and only $3(6.6 \%)$ grade III tumors. Of the 230 patients evaluated, 31 (13.4\%) reported history of sexually transmitted diseases, 17 (54.8\%) patients reporting a history of urethritis and $14(45.2 \%)$ of previous HPV infection.

In relation to pathological variables studied, all patients present squamous cell carcinoma of the penis. The lesion size ranged from $0.3 \mathrm{~cm}$ to $15 \mathrm{~cm}$ (mean $4 \mathrm{~cm}$ ). The initial location of the lesions is shown in Table-2. Based on Broders' classification, 87 patients (37.8\%) had grade I tumors, $131(56.9 \%)$ grade II and only $12(5.3 \%)$ grade III. The clinical and pathological TNM classification is shown in Table-3. Of these patients, $95(41.3 \%)$ had corpora cavernosa or corpus spongiosum infiltration and $40(17.4 \%)$ had urethral invasion. Lymphovascular embolization was observed in 63 patients $(27.3 \%)$ and koilocytosis in $124(53.9 \%)$. Only 3 patients had lung metastases at diagnosis.

The treatment for the patients varied according to the presentation of the primary tumor. Six $(2.6 \%)$ patients were treated with topical 5-fluorouracil cream 5\% due to the presence of carcinoma in situ, 15 (6.5\%) patients underwent circumcision due to lesions limited to the foreskin and $23(10 \%)$ patients were submitted to resection of the primary lesion of superficial tumors less than $4 \mathrm{~cm}$. Partial penile amputation was performed in $142(61.8 \%)$ patients with tumors larger than $4 \mathrm{~cm}$ and/or signs of invasive disease, while a total penectomy was performed in 34 $(14.8 \%)$ patients with extensive lesions and/or signs of invasive disease involving the penile shaft. Only 10 $(4.3 \%)$ patients underwent emasculation due to large tumors with extensive involvement of the penile shaft and scrotum. Of the 230 patients evaluated in this series, $155(67.4 \%)$ underwent bilateral inguinal radical lymphadenectomy to complement treatment of the primary lesion. Of these, 56 (36.1\%) underwent prophylactic lymphadenectomy, $84(54.2 \%)$ therapeutic lymphadenectomy and 15 (9.7\%) lymphadenectomy for advanced disease palliation. The median time between the lesion onset and clinical diagnosis was 13.2 months. After a mean follow-up of 28.8 months we observed a cancer-specific survival of $95.8 \%, 73.4 \%$, $40 \%$ and $35.7 \%$ respectively for patients with lymph node status N0, N1, N2 and N3.

\section{COMMENTS}

Cancer of the penis is a rare neoplasm with low overall incidence. In the United States, it accounts for approximately $0.4 \%$ of men malignancies. In Brazil, despite the high incidence in some regions, this disease accounts for about $2.1 \%$ of male malignancies. $(2,7)$. The incidence of penile cancer varies according to the study area, with its highest incidence reported in the Northeast, representing approximately $5.7 \%$ of malignant neoplasms in men (2). In our study we found that $167(72.7 \%)$ patients were from the Southeast, with $153(91.6 \%)$ born in state of Rio de Janeiro and only 45 (19.5\%) from the Northeast. A recent study by Favorito et al. (8) showed the prevalence of penile cancer in the Southeast and Northeast, with rates of $45.54 \%$ and $41.07 \%$, respectively. Despite the large migration to the Southeast, because it is the most developed economic region in the country, in this study the incidence of the disease was more prevalent in patients born in the state of Rio de Janeiro. These data suggest that many patients with penile cancer receive specific treatment at their home states, with a decline in the interstate migration.

When the cancer of penis is present, it is prevalent in elderly men, with an abrupt increase in incidence during the sixth decade of life and a new 


\section{Epidemiological Aspects of Penile Cancer}

Table 3 - Comparison of clinical TNM staging with the histopathological findings. Using univariate statistical analysis, no statistical difference between the groups was found. In both groups, the absolute prevalence of the disease was for $T 2$.

\begin{tabular}{|c|c|c|}
\hline Tumor Status & Clinical & Histopathological Findings \\
\hline Tis & $7(3.1 \%)$ & $11(4.8 \%)$ \\
\hline $\mathrm{T} 1$ & $29(12.6 \%)$ & $67(29.1 \%)$ \\
\hline $\mathrm{Ta}$ & $0(0 \%)$ & $0(0 \%)$ \\
\hline $\mathrm{T} 2$ & $141(61.3 \%)$ & $105(45.6 \%)$ \\
\hline $\mathrm{T} 3$ & $43(18.7 \%)$ & $40(17.4 \%)$ \\
\hline $\mathrm{T} 4$ & $10(4.3 \%)$ & $7(3.1 \%)$ \\
\hline Total & $230(100 \%$ & $230(100 \%)$ \\
\hline Lymph Nodes Status & Clinical & Histopathological Findings \\
\hline \multirow[t]{5}{*}{ No } & $131(57 \%)$ & $\mathrm{NX}=75(57.3 \%) *$ \\
\hline & & $\mathrm{N} 0=44(33.6 \%)$ \\
\hline & & $\mathrm{N} 1=7(5.3 \%)$ \\
\hline & & $\mathrm{N} 2=3(2.3 \%)$ \\
\hline & & $\mathrm{N} 3=2(1.5 \%)$ \\
\hline \multirow[t]{4}{*}{ N1 } & $24(10.4 \%)$ & $\mathrm{N} 0=13(54.2 \%)$ \\
\hline & & $\mathrm{N} 1=7(29.1 \%)$ \\
\hline & & $\mathrm{N} 2=3(12.5 \%)$ \\
\hline & & $\mathrm{N} 3=1(4.2 \%)$ \\
\hline \multirow[t]{4}{*}{$\mathrm{N} 2$} & $60(26.1 \%)$ & $\mathrm{N} 0=25(41.7 \%)$ \\
\hline & & $\mathrm{N} 1=8(13.3 \%)$ \\
\hline & & $\mathrm{N} 2=18(30 \%)$ \\
\hline & & $\mathrm{N} 3=9(15 \%)$ \\
\hline \multirow[t]{2}{*}{ N3 } & $15(6.5 \%)$ & $\mathrm{N} 2=3(20 \%)$ \\
\hline & & $\mathrm{N} 3=12(80 \%)$ \\
\hline Total & $230(100 \%)$ & $230(100 \%)$ \\
\hline Presence of Distant Metastases & Clinical & \\
\hline M0 & 227 & \\
\hline M1 & 3 & \\
\hline Total & 230 & \\
\hline
\end{tabular}

* These 75 patients staged as $N X$ did not undergo inguinal lymphadenectomy and were followed by observation only.

peak around 80 years of age (9). In our series, we observed only $1.7 \%$ of cases among patients aged between 21-30 years. The percentage increased in the fifth decade of life (20\%) and peaked in the sixth, with an incidence of $26.5 \%$.
The practice of neonatal circumcision seems to be a protective factor in the genesis of cancer of the penis (10). The incidence of penile cancer in the Jewish population, where the practice of neonatal circumcision is universal, is close to zero. In Muslim 


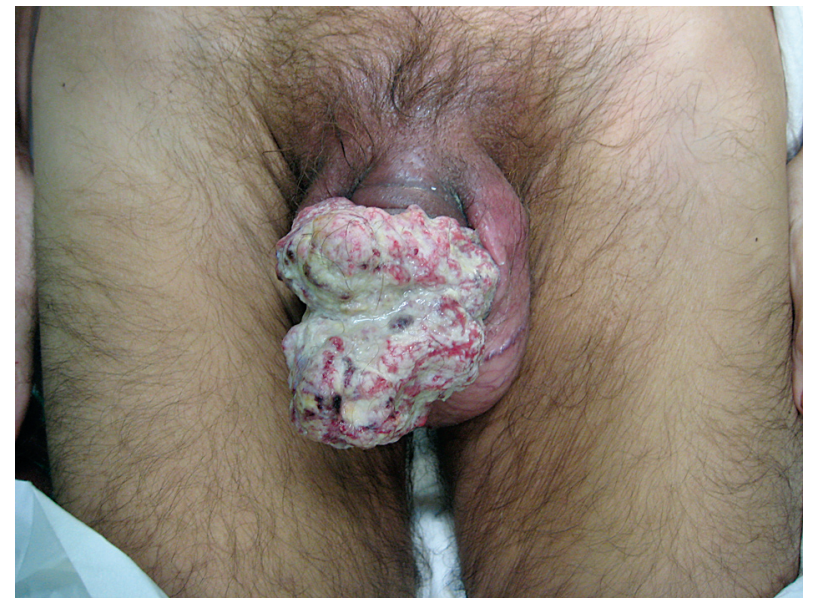

Figure 3 - Penile tumor in an Israeli Jewish patient, who had undergone neonatal circumcision (religious ritual known as Brit-Mila).

countries, where circumcision is performed in childhood beyond the neonatal period, the incidence is up to three times higher (11). In our study, the patients were predominantly Catholic, representing $74.8 \%$ of all cases. Brazil is the largest Catholic country in South America, explaining the high incidence of disease in this religious group. There are only nine reports of penile cancer in circumcised Jews in the neonatal period reported in the literature (12). Interestingly, we had the opportunity to treat an Israeli Jewish patient, who had undergone neonatal circumcision, with an advanced-stage tumor (Figure-3).

Several studies have shown an association between penile cancer and smoking. Hellberg et al. found a relationship between penile cancer and smoking that was direct, dose-related and independent of other known risk factors (12). Harish and Ravi extended these observations by demonstrating that the consumption of products made from tobacco is also related to the incidence of penile cancer independent of other factors (13). In our series, we observed a predominance of smokers, representing $56.5 \%$ of cases. In assessing the degree of tumor differentiation between smokers and nonsmokers, we found no statistical difference between the 2 groups (Table- 4 and Figure-4). This study, despite not having used a control group, showed that more than half of the patients with tumor of the penis were smokers, suggesting that smoking may represent a risk factor for the development of penile cancer. However, the degree of tumor differentiation may not be related to smoking in this series.

An interesting finding in this work concerns the marital status of patients: $58.6 \%$ were married and $24.7 \%$ were single. Since it was not possible to determine any relationship between single marital status and sexual behavior, we were unable to identify any predisposing factor for the genesis of penile cancer related to marital status. It would be reasonable to imagine a lower incidence of penile cancer in patients who were married that theoretically would have a single sexual partner. It is possible that this finding is coincidental and that the only factor associated with this observation is the low economic level of patients and inadequate hygiene conditions, which did not differ between married and single patients.

In the United States, a study by the National Cancer Registries Program revealed an average incidence of 0.7 new cases per 100,000 men in 2001. The incidence ranged from 0.8 for whites, 0.5 for blacks and 0.7 for Hispanics. Although some series have shown no racial predisposition (14), Muir and Nectoux (15) observed a preponderance of 2:1 in black men. In Brazil, due to the great racial miscegenation is hard to separate the patients by ethnicity since one

Table 4 - Stratification of the degree of tumor differentiation (Broders classification) of nonsmokers and smokers with cancer of the penis.

\begin{tabular}{lccc}
\hline Grade & Smokers (\%) & Nonsmokers (\%) & Total (\%) \\
\hline Grade I & $50(38.4)$ & $37(37)$ & $87(37.8)$ \\
Grade II & $73(56.1)$ & $58(58)$ & $131(56.9)$ \\
Grade III & $7(5.4)$ & $5(5)$ & $12(5.3)$ \\
Total (\%) & $130(56.5)$ & $100(43.5)$ & $230(100)$ \\
\hline
\end{tabular}




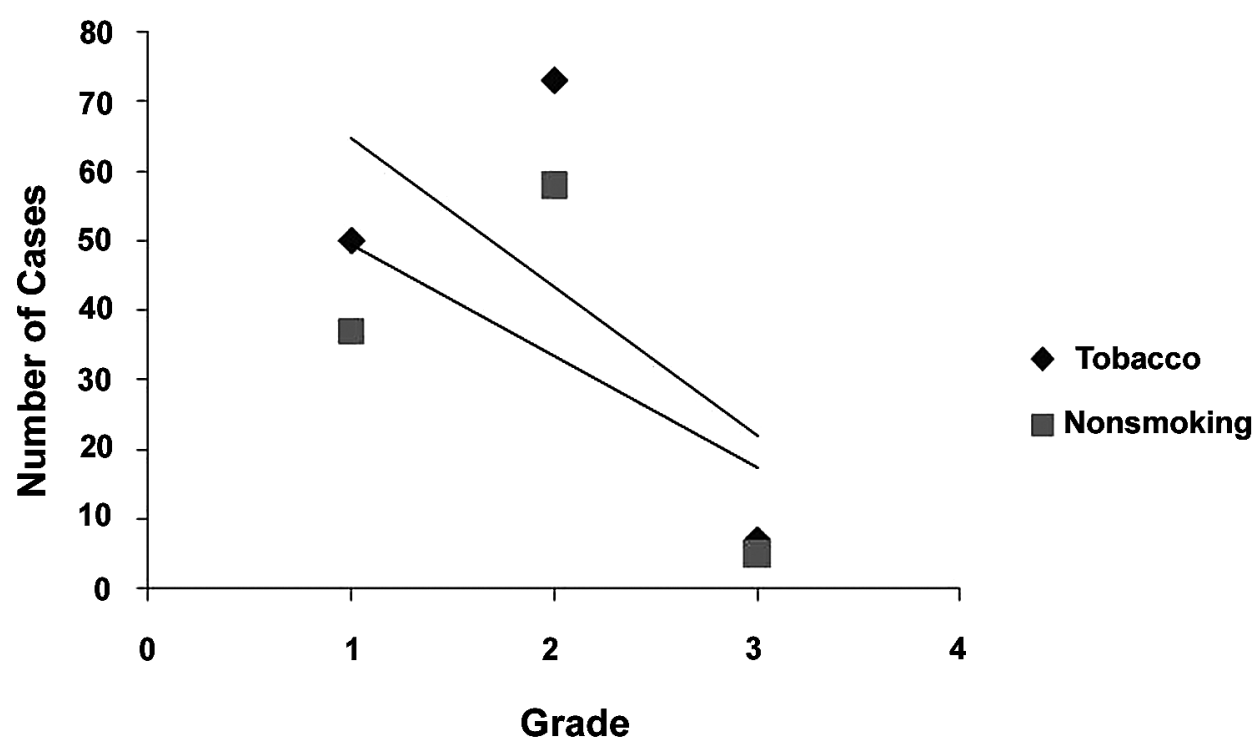

Figure 4 - In this case no linear correlation was found using regression analysis of 0.35 and 0.41 respectively for smokers and nonsmokers.

cannot accurately differentiate blacks, browns and whites. Some authors suggest a higher likelihood of African-Americans to develop more aggressive forms of the disease than white patients (16). In our series, only 20 patients $(8.8 \%)$ were black, and of these, twelve had grade 1 tumors, seven had grade 2 tumors and only one had a grade 3 tumor. Thus, we did not observe more aggressive disease in black patients compared to whites.

The mechanism of tumor induction and promotion related to human papilloma virus (HPV) infection is not completely understood. It is believed that the incorporation of viral DNA to the human genome leads to hyper-expression of E6 and E7 and inactivates the host cell's tumor suppressor gene products $\mathrm{p} 53$ and $\mathrm{pRb}$ (17). The identification of HPV in specimens of penile tumors varies with the investigatory technique, ranging from 30 to $100 \%$ (18-20). Using koilocytosis to detect the presence of HPV in tumor tissue, we found positive readings in 124 patients $(53.9 \%)$. The cytological and histological diagnoses, despite showing good specificity (90\%), showed low sensitivity. Only $30 \%$ to $60 \%$ of patients with HPV infection are correctly identified by these methods $(17,21,22)$. In another study conducted by our group, it was possible using a more sophisticated method to detect HPV DNA in $75 \%$ of patients with invasive carcinomas (23).

Sexually transmitted diseases like herpes, urethritis and syphilis have been implicated as a possible risk factor for the development of penile cancer, however no convincing evidence was found linking them to this disease $(5,12)$. In our series $13.4 \%$ of patients reported having had in the past at least one episode of sexually transmitted diseases (STDs), 17 (54.8\%) had urethritis and $14(45.2 \%)$ presented HPV infection. A possible explanation of the association between penile cancer and STDs is the fact that the patients with STDs have a higher number of sexual partners, increasing the likelihood of HPV infection.

Phimosis is considered an important risk factor for the development of penile cancer, and is found in approximately $25-75 \%$ of patients with this cancer in the largest series (3-5). It has been proposed that inadequate hygiene of the preputial sac with consequent accumulation of smegma leads to a chronic local inflammatory process, contributing to the genesis of penile cancer. In our study we found 68 patients $(29.6 \%)$ with phimosis and 46 patients $(20 \%)$ who had been circumcised. Of these patients, 45 (97.8\%) 
had undergone the procedure in childhood or adulthood and only one $(2.2 \%)$ in the neonatal period, corroborating the literature data and suggesting the inefficiency of circumcision after the neonatal period to prevent cancer of the penis $(5,7,8,12,24)$. There are few studies in the literature that correlate the degree of tumor differentiation in the presence or absence of prior circumcision. Favorito et al. (8) reported in their study that among 37 patients with squamous cell carcinoma of penis circumcised before the appearance of the tumor, 31 had grade 1 tumor $(83.8 \%), 2$ (5.4\%) had grade 2 tumor and 4 had (10.8\%) grade 3 tumor. A study conducted by Seyam et al. (25) demonstrated that among 21 patients with squamous cell carcinoma of penis with a history of previous circumcision, the incidence of grade 1, 2 and 3 tumors was respectively, $36.4 \%, 50 \%$ and $4.5 \%$. In our series, more than half (54.4\%) of our circumcised patients presented grade 1 tumors. Although late circumcision does not confer any protection against the squamous cell carcinoma of the penis, its performance may be related to the development of less aggressive lesions. One possible explanation is the exposure of the glans in a period that precedes the appearance of the lesions, allowing for earlier identification of tumor, and the elimination of chronic local irritating factors.

There is a strong association between the clinical stage of the primary penile lesion and the development of inguinal metastases. Involvement of the corpus cavernosum, the corpus spongiosum and/or urethra are considered important risk factors, predisposing the development of inguinal metastases in $61 \%$ to $75 \%$ of cases $(1,26,27)$. Lymphovascular embolization is also related to poor prognosis. In contrast, patients who present koilocytosis have shown better survival (28). In this series Lymphovascular embolization was observed in 63 patients $(27.3 \%)$ and koilocytosis in $124(53.9 \%)$.

In our study we found that 152 patients (66.1\%) had invasive disease (pt2, pt3 and pt4) and the average time elapsed between the lesion onset and clinical diagnosis was 13.2 months. This long delay in diagnosis and treatment of patients is associated with poor access to public health services and little available information about the disease, reflecting the low socioeconomic level of patients most affected by this disease.
The 2002 TNM classification for the staging of tumors of the penis has been criticized by several authors $(17,29-31)$. Because it is essentially a pathological assessment it is virtually impossible to clinically determine the precise level of tumor invasion and the real lymph node status. In the study by Petralia et al. (30), physical examination was able to properly stage the primary tumor in only eight of 13 patients $(61.5 \%)$, with overstaging in $2(15.4 \%)$ and understaging in the other three (23.1\%) patients. Likewise de Kerviler et al. (32) only obtained a correct clinical staging of penile lesions in $66.6 \%$ of patients in their series. In our study we observed clinical staging accuracy of the primary tumor in $75.2 \%$ of cases. When stratifying patients according to the primary tumor, understaging was observed in $14.3 \%$ of patients with Tis and overstaging in $17.2 \%, 29.8 \%, 13.9 \%$ and $30 \%$ respectively for $\mathrm{T} 1, \mathrm{~T} 2, \mathrm{~T} 3$ and $\mathrm{T} 4$ tumors. Misinterpretation of the degree of tumor infiltration of the primary lesion on physical examination could be attributed to local edema and infectious processes that arise at tumor site.

The presence and extent of inguinal metastases are the most important prognostic factors related to survival of patients with squamous cell carcinoma of the penis $(1,4,16,17)$. In our series, of the 230 patients evaluated we found that $131(57 \%)$ presented clinical lymph node status N0, $24(10.4 \%)$ were at stage N1, $60(26.1 \%)$ were at stage N2 and $15(65 \%)$ were at stage N3. Despite the presence of clinically positive lymph nodes in $43 \%$ of the cases, one must take into account the inaccuracy of inguinal clinical staging, where under-staging errors of up to $20 \%$ are observed in patients with lymph node status N0 and over-staging in $50 \%$ of patients with palpable lymph nodes $(33,34)$. In our series we observed a failure leading to understaging in $21.4 \%$ of patients with clinical N0 lymph node status. Overstaging occurred in $38.4 \%$ of patients with palpable lymph nodes (Table-3).

\section{CONCLUSION}

Cancer of the penis is a rare neoplasm in Rio de Janeiro, mainly affecting patients born in this state and with low socioeconomic status. The epidemiological profile of these patients revealed that they 
were white, married, smoker, uncircumcised, Catholic and sixty or older. It was not possible to accurately determine the prevalence of HPV infection based only on detection of koilocytosis in tumor tissue. Poorer patients with less education tend to delay longer in seeking medical help, and therefore the diagnosis of the disease is frequently performed in the advanced stages.

\section{CONFLICT OF INTEREST}

None declared.

\section{REFERENCES}

1. Solsona E, Algaba F, Horenblas S, Pizzocaro G, Windahl T; European Association of Urology: EAU Guidelines on Penile Cancer. Eur Urol. 2004; 46: 18.

2. Brunini R: Câncer no Brasil: Dados histopatológicos: 1976-80, Ministério da Saúde - Campanha Nacional de Combate ao Câncer, 1982.

3. Barrasso R, De Brux J, Croissant O, Orth G: High prevalence of papillomavirus-associated penile intraepithelial neoplasia in sexual partners of women with cervical intraepithelial neoplasia. N Engl J Med. 1987; 317: 916-23.

4. Maiche AG: Epidemiological aspects of cancer of the penis in Finland. Eur J Cancer Prev. 1992; 1: 153-8.

5. Maden C, Sherman KJ, Beckmann AM, Hislop TG, Teh CZ, Ashley RL, et al.: History of circumcision, medical conditions, and sexual activity and risk of penile cancer. J Natl Cancer Inst. 1993; 85: 19-24.

6. Cubilla AL, Reuter V, Velazquez E, Piris A, Saito S, Young RH: Histologic classification of penile carcinoma and its relation to outcome in 61 patients with primary resection. Int J Surg Pathol. 2001; 9: 11120.

7. Parkin DM and Muir CS: Cancer Incidence in Five Continents. Comparability and Quality of Data. Lyon. IARC 1992; pp. 45-173.

8. Favorito LA, Nardi AC, Ronalsa M, Zequi SC, Sampaio FJ, Glina S: Epidemiologic study on penile cancer in Brazil. Int Braz J Urol. 2008; 34: 587-91; discussion 591-3.

9. Persky L: Epidemiology of cancer of the penis. Recent Results Cancer Res. 1977; 60: 97-109.
10. Licklider S: Jewish penile carcinoma. J Urol. 1961; 86: 98.

11. Tan RE: Observations on frequency of carcinoma of the penis at Macassar and its environs (South Celebes). J Urol. 1963; 89: 704-5.

12. Hellberg D, Valentin J, Eklund T, Nilsson S: Penile cancer: is there an epidemiological role for smoking and sexual behaviour? Br Med J (Clin Res Ed). 1987; 295: 1306-8.

13. Harish K, Ravi R: The role of tobacco in penile carcinoma. Br J Urol. 1995; 75: 375-7.

14. Beggs JH, Spratt JS Jr: Epidermoid carcinoma of the penis. J Urol. 1964; 91: 166-72.

15. Muir CS, Nectoux J: Epidemiology of cancer of the testis and penis. Natl Cancer Inst Monogr. 1979; 53: $157-64$.

16. Busby JE, Pettaway CA: What's new in the management of penile cancer? Curr Opin Urol. 2005; 15: 350-7.

17. Peclat de Paula AA, Neto JCA, Cruz AD, Júnior RF: Carcinoma epidermoide do pênis: considerações epidemiológicas, histopatológicas, influência viral e tratamento cirúrgico. Revista Brasileira de Cancerologia. 2005; 51: 243-52.

18. Bezerra AL, Lopes A, Santiago GH, Ribeiro KC, Latorre MR, Villa LL: Human papillomavirus as a prognostic factor in carcinoma of the penis: analysis of 82 patients treated with amputation and bilateral lymphadenectomy. Cancer. 2001; 91: 2315-21.

19. McCance DJ, Kalache A, Ashdown K, Andrade L, Menezes F, Smith P, et al.: Human papillomavirus types 16 and 18 in carcinomas of the penis from Brazil. Int J Cancer. 1986; 37: 55-9.

20. Sarkar FH, Miles BJ, Plieth DH, Crissman JD: Detection of human papillomavirus in squamous neoplasm of the penis. J Urol. 1992; 147: 389-92.

21. Trofatter KF Jr: Diagnosis of human papillomavirus genital tract infection. Am J Med. 1997; 102: 217.

22. de Paula AA, Netto JC, Freitas R Jr, de Paula LP, Mota ED, Alencar RC: Penile carcinoma: the role of koilocytosis in groin metastasis and the association with disease specific survival. J Urol. 2007; 177: 1339-43; discussion 1343.

23. Scheiner MA, Campos MM, Ornellas AA, Chin EW, Ornellas MH, Andrada-Serpa MJ: Human papillomavirus and penile cancers in Rio de Janeiro, Brazil: HPV typing and clinical features. Int Braz J Urol. 2008; 34 : 467-74; discussion 475-6.

24. Thomas JA, Small CS: Carcinoma of the penis in Southern India. J Urol. 1968; 100: 520-6. 
25. Seyam RM, Bissada NK, Mokhtar AA, Mourad WA, Aslam M, Elkum N, et al.: Outcome of penile cancer in circumcised men. J Urol. 2006; 175: 557-61; discussion 561 .

26. Slaton JW, Morgenstern N, Levy DA, Santos MW Jr, Tamboli P, Ro JY, et al.: Tumor stage, vascular invasion and the percentage of poorly differentiated cancer: independent prognosticators for inguinal lymph node metastasis in penile squamous cancer. J Urol. 2001; 165: 1138-42.

27. McDougal WS: Carcinoma of the penis: improved survival by early regional lymphadenectomy based on the histological grade and depth of invasion of the primary lesion. J Urol. 1995; 154: 1364-6.

28. Ornellas AA, Nóbrega BL, Wei Kin Chin E, Wisnescky A, da Silva PC, de Santos Schwindt AB: Prognostic factors in invasive squamous cell carcinoma of the penis: analysis of 196 patients treated at the Brazilian National Cancer Institute. J Urol. 2008; 180: 1354-9.

29. Horenblas S, van Tinteren H: Squamous cell carcinoma of the penis. IV. Prognostic factors of survival: analysis of tumor, nodes and metastasis classification system. J Urol. 1994; 151: 1239-43.
30. Petralia G, Villa G, Scardino E, Zoffoli E, Renne G, de Cobelli O, et al.: Local staging of penile cancer using magnetic resonance imaging with pharmacologically induced penile erection. Radiol Med. 2008; 113: 51728.

31. Leijte JA, Gallee M, Antonini N, Horenblas S: Evaluation of current TNM classification of penile carcinoma. J Urol. 2008; 180: 933-8; discussion 938.

32. de Kerviler E, Ollier P, Desgrandchamps F, Zagdanski AM, Attal P, Teillac P, et al.: Magnetic resonance imaging in patients with penile carcinoma. Br J Radiol. 1995; 68: 704-11.

33. Ornellas AA, Seixas AL, Marota A, Wisnescky A, Campos F, de Moraes JR: Surgical treatment of invasive squamous cell carcinoma of the penis: retrospective analysis of 350 cases. J Urol. 1994; 151: 1244-9.

34. McDougal WS, Kirchner FK Jr, Edwards RH, Killion LT: Treatment of carcinoma of the penis: the case for primary lymphadenectomy. J Urol. 1986; 136: 3841.

\section{Correspondence address:}

Dr. Antonio Augusto Ornellas

Department of Urology

Instituto Nacional de Câncer

Praça da Cruz Vermelha, 23

Rio de Janeiro, RJ, Brazil

E-mail: ornellasa@hotmail.com

\section{EDITORIAL COMMENT}

Koifman et al. report on their experience with a relatively large prospective series of men with penile cancer, a rare disease. The findings of this contemporary series are interesting and useful for public health strategies. So what is new on demographics and treatment of penile cancer? As it has been previously shown, the Northern regions of Brazil have the highest rates of penile cancer (1), and national prevention campaigns have focused these regions. However, it has been observed that men treated in 
Rio de Janeiro were mostly from Rio de Janeiro and not migrants as in past decades, and therefore local campaigns are also important.

Maybe the most important aspect when treating men with penile cancer remains inguinal nodes staging. Koifman et al. report about $10 \%$ of false negatives and close to $50 \%$ false positive nodes. However, only when better staging modalities become available can treatment become less aggressive. In this series, all patients who were indicated for adjunctive inguinal treatment underwent radical bilateral inguinal lymphadenectomy, what we see as a good adjunctive approach. When modified procedures were described, initial experience made us believe that they could be advantageous, but the possibility of leaving disease behind has reduced interest for the modified procedures. For this reason radical procedures seem to become a trend again in contemporary series $(2,3)$.

\section{EDITORIAL COMMENT}

In this epidemiological study by Koifman et al., the authors detail the prevalence of penile cancer in 3 public hospitals within Brazil over a 6 year period. Of the 230 patients with penile cancer described in this series, the majority of patients originated from the southeast region of Brazil, with only a small subset $(2.2 \%)$ having undergone neonatal circumcisions. Phenotypically, these patients presented in most instances with low to intermediate grade tumors, with one-quarter of patients exhibiting lymphovascular invasion. This study highlights that delay in diagnosis remains a major limitation in the care of penile cancer patients, with the median time to diagnosis being 13.2 months.

I applaud the authors for their very insightful study. There are several important clinical lessons learned from the present study. Firstly, teaching and public education in the prevention, signs, and symptoms of penile cancer remains a major limitation in optimizing the outcomes of this disease on patients.

\section{REFERENCES}

1. Favorito LA, Nardi AC, Ronalsa M, Zequi SC, Sampaio FJ, Glina S: Epidemiologic study on penile cancer in Brazil. Int Braz J Urol. 2008; 34: 587-91; discussion 591-3.

2. Caso JR, Rodriguez AR, Correa J, Spiess PE: Update in the management of penile cancer. Int Braz J Urol. 2009; 35: 406-15.

3. Korkes F, Moniz RR, Castro MG, Guidoni LRM, Fernandes RC, Perez MDC: Modified inguinal lymphadenectomy for penile carcinoma has no advantages. JAS. 2009; 16: 33-6.

Dr. Fernando Korkes Assistant Professor Division of Urology, ABC Medical School Av. Príncipe de Gales, 821 Santo André, SP, 09060-650, Brazil E-mail:fkorkes@terra.com.br

This is probably the one area in which we as clinicians can most greatly impact the care of our patients and in the community at large. Secondly, I was somewhat surprised to note that only a small subset of the patients within this study had high grade (Grade 3) tumors whereby illustrating that there may in fact exist significant heterogeneity within the pathophysiology of penile cancer worldwide as other series have reported a greater proportion (typically $25-50 \%$ ) of patients exhibiting higher grade penile tumors. This may similarly impact our surgical approach to penile cancer. As we embark in this new era of risk-adapted and personalized cancer care, the goals of treatment have become to optimize oncological outcome while preserving quality of life. In this regard, a highly selective approach to penile preserving surgery and/or ablation for low grade/stage primary penile tumors is gaining popularity and acceptance among penile cancer experts. In contrast, a multimodal approach (typically using systemic chemotherapy followed 
by surgery) for locally advanced and metastatic penile cancer is rapidly becoming accepted as the most suitable approach for advanced disease. In addition, targeted therapy (aimed at the EGFR or other altered pathways) will likely redefine the therapeutic armamentarium to advanced penile cancer in the coming years.

\author{
Dr. Philippe E. Spiess \\ Assistant Professor of Urologic Oncology \\ H. Lee Moffitt Cancer Center \\ Tampa, FL, USA \\ E-mail:Philippe.Spiess@moffitt.org
}

\section{EDITORIAL COMMENT}

While science is advancing at a tremendous speed and most research is focusing on a molecular basis and treatment improvement including minimally invasive resources (1) as well as new technologies for penile reconstruction, a holistic view is fundamental, especially for diseases carrying obscure facets such as the misunderstood behavior involved in penile cancer patients.

Though the current work presents important limitations once data showed are deemed to selection and measurement biases among others, this study has the potential to highlight and put forward the main aspects to future studies including interventional protocols.

Why over a year for a diagnosis in a much required (urinary, sexual and reproductive functions), external and easily auto-examinable organ?

The median time between the lesion onset and clinical diagnosis was 13.2 months which involved most patients presenting invasive disease, diagnosed in advanced stages, imposing mutilating and devastating treatments and certainly impacting on quality and quantity of life.

Authors have stated that the long delay in diagnosis and treatment of patients is associated with poor access to public health services and little available information about disease, reflecting the low socioeconomic level of patients most affected by this disease.

This is possibly the most alarming information presented and should be better explored in future studies in a more comprehensive manner.
Previous studies have identified that although there is strong evidence of an association between lower socio-economic status and delay for urological cancers, diagnosis and treatment nonrecognition of symptom seriousness is the main patient-mediated factor resulting in increased time to presentation. Additionally, fear of cancer is a contributor to delayed presentation. On the other hand, 'misdiagnosis' occurring either through treating patients symptomatically or relating symptoms to a health problem other than cancer is important and this could also be linked to inadequate patient examination, use of inappropriate tests or failing to follow-up negative or inconclusive test results (2).

For penile cancer, while the major source of delay results from patient reluctance to seek medical advice (3), approximately one-fifth of patients with penile cancer are first referred to specialties other than Urology. This diagnostic delay potentially affects the overall prognosis and thus, the greatest impact in this condition is likely to be achieved by increased public awareness and education.

In this regard epidemiological characteristics could be a small evident part of something largely hidden, the clues to the tips of the iceberg masked behind psychological and emotional aspects possibly structured by a mixture of social and faith taboos.

This is the (very high) cost of a miscellaneous of fear, ignorance and deep-rooted taboos warranting further studies urgently. Bias and preconception related to the penile cancer diagnosis and treatment 
are under recognized and poorly understood; further studies are needed once the epidemiological aspects suggest a great and important role for prejudice in penile cancer dangerousness.

The penis being a noble organ and cancer a serious illness, the fact that penile cancer is neglected is a paradox. There is probably some mystic significance for penis and cancer that could explain in part the upsetting data shown. The over a year delay in diagnosis is conjectured to be related to male and target organ factors once other urological cancers are more readily diagnosed compared to penile cancer.

In this scenario, as for prostate cancer (4), the discovery of the factors behind it will serve to render the patient information more fundamental towards a less deterministic and less self-destructive behavior. Added to this is an endless behavior world to be unveiled as recognized recently (5), opening a broad and under explored avenue in the study of penile cancer.

Greek god Priapus teaches that the phallus is the source of life, beauty, joy, and pleasure. The symbolic version of the phallus, a phallic symbol is meant to represent male generative powers. Men are positioned as men insofar as they are seen to have the phallus. The symbolic phallus is the concept of being the ultimate man, and having this is compared to having the divine gift of God.

Although there is a worldwide geographic variation in incidence that could be caused by differences in socioeconomic status, hygiene, religious and cultural conditions, fear of mutilation or damage caused by the treatment, and other misunderstanding about the possible causes of cancer, impede the process of seeking testing for early diagnosis and treatment. Consequent anxiety leads to distortion in communication, creating difficulty in the comprehension of the information and recommendations, with detriment to the doctor-patient relationship (4).

Future studies should be concerned with the vital issue in human research: the cultural scenario that clearly manifests global inequality and contrasting behavioral differences around the world (6).

It highlights the need for individualized approaches to help men address their thoughts and feelings about being diagnosed with urological can- cers. These efforts should include strategies that address cultural beliefs and values related to temporal orientation.

More research and public education are necessary, with information campaigns addressing men's emotional attitudes. It is our hope that by changing perceptions, providing empathy, respect and focusing on the perception of the person's own body, it is possible that each individual could find their own way to a satisfactory way of living, resulting in a better quality of life, significantly impacting penile cancer.

\section{REFERENCES}

1. Tobias-Machado M, Correa WF, Reis LO, Starling ES, Neves OC, Juliano RV, Pompeo ACL. SingleSite Video Endoscopic Inguinal Lymphadenectomy (SSVEIL): Initial Report. J Endourol. (in press).

2. Macleod U, Mitchell ED, Burgess C, Macdonald S, Ramirez AJ: Risk factors for delayed presentation and referral of symptomatic cancer: evidence for common cancers. Br J Cancer. 2009; 101(Suppl 2): S92-S101.

3. Lucky MA, Rogers B, Parr NJ: Referrals into a dedicated British penile cancer centre and sources of possible delay. Sex Transm Infect. 2009; 85: 527-30.

4. Naccarato AM, Reis LO, Matheus WE, Ferreira U, Denardi F: Barriers to prostate cancer screening: psychological aspects and descriptive variables \&\#x2013; is there a correlation? Aging Male. 2010; 12. [Epub ahead of print]

5. Zequi SC, Guimaraes GC, da Fonseca FP, Lopes A, Matheus WE, Reis LO, et al. Sex with Animals (SWA): Characteristics and Possible Associations with Penile Cancer and Sexually Transmitted Diseases. Actual Results of a Multicentric Brazilian CaseControl Study. J Urol 2010; 183(Suppl 4): e8.

6. Oliveira Reis L: Translating questionnaires for use in crosscultural research--are we doing the right thing? Actas Urol Esp. 2009; 33: 5-7.

Dr. Leonardo Oliveira Reis

Division of Urologic Oncology, School of Medicine University of Campinas, UNICAMP

Campinas, SP, Brazil

E-mail: reisleo@unicamp.br 